\title{
UV-light-induced curing of branched epoxy novolac resin for coatings
}

\author{
S. Gaidukovs ${ }^{1,2 *}$, A. Medvids $^{2}$, P. Onufrijevs ${ }^{2}$, L. Grase $^{3}$ \\ ${ }^{1}$ Institute of Polymer Materials, Faculty of Materials Science and Applied Chemistry, Riga Technical University, \\ P. Valdena 3/7, LV-1048 Riga, Latvia \\ ${ }^{2}$ Institute of Technical Physics, Faculty of Materials Science and Applied Chemistry, Riga Technical University, \\ P. Valdena 3/7, LV-1048 Riga, Latvia \\ ${ }^{3}$ Institute of Silicate Materials, Faculty of Materials Science and Applied Chemistry, Riga Technical University, \\ P. Valdena 3/7, LV-1048 Riga, Latvia
}

Received 1 March 2018; accepted in revised form 22 May 2018

\begin{abstract}
UV-light induced curing of the branched epoxy novolac resin (ENR) is reported. Cross-linked ENR coatings with a thickness of $150 \mu \mathrm{m}$ were produced by the cationic photopolymerization of poly((phenyl glycidyl ether)-co-formaldehyde), which was photoinitiated by bis(4-dodecylphenyl)-iodonium hexaflurorantimonate. ENR crosslinking efficiency of UVlight polymerization accomplished by $\mathrm{Hg}$-lamp with a power of $1 \mathrm{~kW}$ continuous irradiation was investigated as a function of the photoinitiator content and UV curing time. Optimal cross-linking properties were observed for photoinitiator concentration of $1.5 \%$, and curing time $5 \mathrm{~min}$. It was found that higher Vickers hardness of the polymer resulted in an increased cross-linking density of the developed chain network. UV irradiation time longer than 6 min results in the photodegradation of the polymer. This was confirmed by scanning electron microscopy investigations of polymer surface microstructure, as well as complemented by Fourier transform infrared (FTIR), ultraviolet-visible (UV-VIS) and Raman spectroscopy measurements that evidence the oxygen containing groups. Furthermore, the developed ENR photopolymerization technology can be used to obtain protective coatings for applications in power generation and maritime industries where thermal curing processes and two-component resin hardening are unacceptable.
\end{abstract}

Keywords: coatings, photopolymerization, branched epoxy novolac resin, UV curing

\section{Introduction}

Usually, the processing technology of the thermoset polymers is characterized by the use of the two component formulations, which generally consist of a polymer resin and a hardener. These two component polymer formulations need to be hardened for almost 12 hours at room temperature $[1,2]$. Generally, extra heating at $60-160^{\circ} \mathrm{C}$ is necessary to facilitate the hardening process [3]. The conventional curing process has several relevant disadvantages. Firstly, as the prerequisite condition for acceptable final properties of the produced material, the following thermal treatment is always desirable as a post-curing process [4]. Secondly, there are difficulties with producing large monolith constructions and coating large surfaces that can be sensitive to heating and/or when heating is even impossible [5]. For example, the repair service protective coatings applications for ships in the maritime industry, and for power generators in the energy generation sector [6].

The market of ultraviolet (UV) curable polymers is growing very rapidly, especially in the last decades [7]. This market is anticipated to grow by $7.0 \%$ from 2013 to 2019 and is expected to reach USD 7.930

$\overline{{ }^{*} \text { Corresponding author, e-mail: sergejs.gaidukovs@rtu.lv }}$ (C) BME-PT 
million by 2019 [8]. It is related to many essential benefits of the UV curing technology. Furthermore, simplicity along with increased productivity and adjustable exploitation properties are the principal acquisition of this technology in comparison to other conventional methods of curing [9]. For example, unlike conventional thermal curing, irradiation curing has a time in the order of minutes [10] and is considered to be a green technology without the use of volatile organic solvents [11]. The use of irradiation curing frequently leads to energy, space and financial savings.

Different chemical raw monomers, oligomers and pre-polymers of acrylates, urethanes, and their copolymers have been shown to be easily photopolymerized by irradiation through the radical reaction mechanism with or without the addition of photoinitiator and photosensitizer additives $[12,13]$. However, the polymerization of epoxides, also known as oxirane rings opening polymerization, is generally photoinitiated by the small loadings of photogenerators and governed by cationic polymerization reactions [14]. This occurs by means of the photolysis of diaryliodonium and triarylsulfonium salts, which is based on the production of strong protonic acids [15]. Commonly, intensive irradiation is necessary for the initiation of photoacid generation and cationic polymerization reactions [16], while photoacid content is maintained in the range of $1-5$ parts per hundred resin (phr) in the bulk liquid monomer [17].

It should also be mentioned that diverse electromagnetic irradiation sources can be applied for photopolymerization curing. Therefore, visible light, UVlamps (Hg lamps, UV-LEDs), X-ray generators and accelerated electron beam guns have been successfully used for the photo-curing process [17-20]. The use of excimer lasers and femtosecond lasers are common for photolithography technology issues [21, 22]. In particular, UV-curing technology has shown the best perspectives from the point of the wide industrial application and nanofabrication [23]. The UV region is formally divided according to the wavelength and energetic content in three different domains: UV-A, characterized by wavelengths in the range 315-400 nm, UV-B, with wavelengths between 315 and $280 \mathrm{~nm}$ and UV-C with wavelengths ranging from 280 to $100 \mathrm{~nm}$ [24]. UV-B and UV-C are commonly employed to induce the photopolymerization reaction [25].
The traditional phenol-formaldehyde resins (PFR) are highly cross-linked polymers with very broad application. These well-established thermoset plastics are synthesized from their low molecular weight precursor of novolac or resole type, which are commonly thermally cured and catalyzed by the addition of strong acid or alkali compounds [26]. PFR exhibit good heat-resistant, flame-retardant and dielectric properties. PFR have good processability and relatively low cost. Therefore, they are widely applied for composites manufacturing and are broadly used in construction, households, and electrical facilities [27]. However, there are several serious concerns regarding their application: the use of phenol in their production, the release of formaldehyde to the environment during exploitation, and the brittleness of PFR materials [28]. To get rid of these limitations, a novel functionality of oxirane rings is introduced to the polymer of novolac or resole [26]. Thereto, generally, linear epoxy novolac resins (ENR) are synthesized by reacting a phenolic novolac or resole with epichlorohydrin [29]. These ENR precursors contain more than 2 epoxy groups per molecule and can therefore be described as multifunctional polyepoxide resins. Cured ENR provide a very high cross-link density due to the increased functionality attributed to the of epoxy groups [30]. Incorporation of the epoxy groups into the phenol-formaldehyde macromolecular chain backbone can further improve adhesion, strength, stiffness, thermal, dimensional stability, chemical and solvent resistance [31]. These ENR resins are used in formulations for high performance applications requiring excellent chemical resistance to acids, caustics, solvents, oxidizing agents, as well as solvent resistance and high temperature resistance than the standard Bisphenol A epoxy resins [32]. ENR products for exceptionally high corrosion resistance coatings and linings can be found on the market today [33]. However, the broad application of ENR is limited by their poor liquidity properties at room temperature and as well as need to be heat cured [33]. For that matter, only low molecular weight and linear macromolecular chain resins are applied [34].

This study was directed at expanding the applications limits of ENR using a branched epoxy novolac polymer, a cationic photoinitiator additive, and applying a UV-light photocuring technology with future possible applications as coating formulations in 
the maritime and the energy industry sectors. We can conclude that the thermal curing of the two component resins is not efficient for polymer coating on the high thermal conductive and capacitive materials, for instance, polymer on massive metal systems. Therefore, the aim of the current investigation is to show the possibility of the photopolymerization of the branched ENR on steel using the UV-light curing method.

\section{Experimental}

\subsection{Materials and sample preparation}

The branched poly(phenyl glycidyl ether)-co-formaldehyde (Figure 1), obtained from Advanced Polymer Coatings (USA), was used as ENR for the photopolymerization synthesis. The resin's viscosity is $2000 \mathrm{mPa} \cdot \mathrm{s}$, and specific gravity is $1.21 \mathrm{~g} / \mathrm{cc}$. The UV 1242 cationic photoinitiator $(P I)$ bis(4-dodecylphenyl) iodonium hexafluorantimonate was obtained from Deuteron GmbH (Germany). Hereafter, PI for the photoinitiator will be used in the text. As a reactive diluent, $\mathrm{C}_{12}-/ \mathrm{C}_{14}$-glycidylether was applied. Its content was maintained at approx. 1 part per 1 part of PI. Their chemical structures are shown in Figure 1. Acetone $(>99.5 \%)$ was obtained from Aldrich. For reference, on commercially two-component ENR formulation was used. The commercial mixture of amine and imidazole, obtained from Advanced Polymer Coatings, was used as a curing agent.

Samples were prepared by solution casting and UV curing method. First, liquid mixtures of poly(phenyl glycidyl ether)-co-formaldehyde with a pre-calculated amount of bis(4-dodecylphenyl) iodonium hexaflurorantimonate and toluene were blended in a glass flask. The bis(4-dodecylphenyl) iodonium hexafluorantimonate blend with $50 \mathrm{wt} \% \mathrm{C}_{12}-/ \mathrm{C}_{14}$-glycidylether was used in the preparations. The real weight content of the photoinitiator in the epoxy compound was adjusted $0.5,1.5$ and 3 and $6 \mathrm{wt} \%$. The mixtures of photoinitiator $(P I)$, ENR were coated on a commercially available glass slides and steel plates. No special preparations of the substrate surface were applied to the specimens. Finally, the coating films were cured at room temperature for 1, 3, 5, 10, 20, and $50 \mathrm{~min}$ under UV irradiation with $96.5 \mathrm{~W} / \mathrm{cm}^{2}$ intensity and at a distance of $13 \mathrm{~cm}$ from the irradiation source. The coating thickness was in the range 120-170 $\mu \mathrm{m}$. Accordingly, a $1000 \mathrm{~W} \mathrm{Hg}$ deep UV exposure lamp with broad emission spectral range from 200-600 nm was utilized for photopolymerization curing experiments in air environments.

Additionally, the conventional two-component hardening of the ENR was also used for comparison reasons. The commercial mixture of amine and imidazole in stoichiometric ratio was used for this experiment. The thermal curing process of the ENR coating on steel was carried out at $80^{\circ} \mathrm{C}$ for $4 \mathrm{~h}$.

\subsection{Testing methods}

Morphological investigation of the samples was performed with a Schottky Field Emission scanning electron microscope (FE-SEM) (Nova NanoSEM 650, FEI Company, Eindhoven, The Netherlands) using low vacuum mode. Charge reduction $\mathrm{C}$ or metallic films were not deposited on the samples studied. The following parameters of the SEM analysis were used:
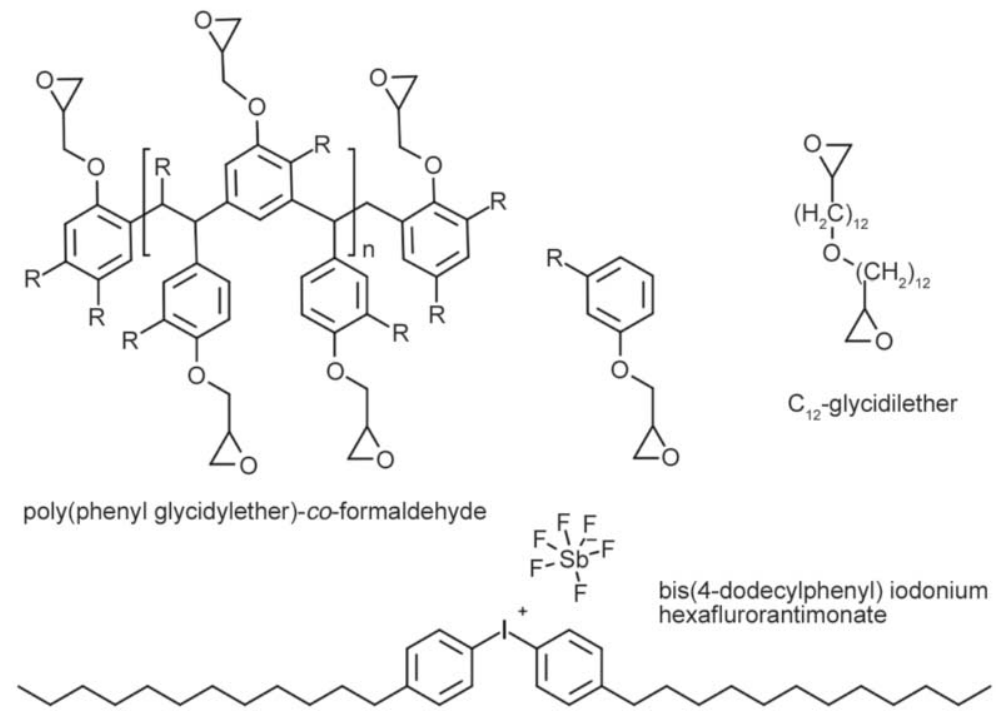

Figure 1. Structure of branched epoxy novolac resin, photoinitiator and active diluent. 


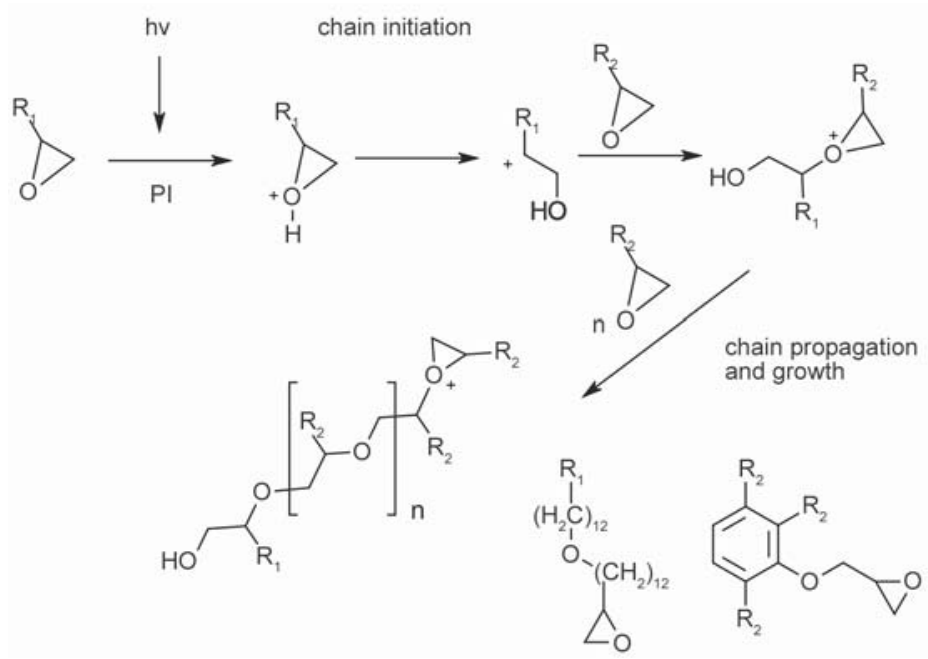

Figure 2. Possible photopolymerization initiation mechanism of branched epoxy novolac resin rendering polyether structures.

accelerating voltage $5 \mathrm{kV}$, working distance $5 \mathrm{~mm}$ and spot size 3 .

Absorption spectra in the range $500-4000 \mathrm{~cm}^{-1}$ were measured on VERTEX 70/70v FTIR spectrometer equipped with the MIRacle ATR Accessory.

The room temperature Raman spectra of the samples were measured by Renishaw InVia90V727 microRaman spectrometer with a laser excitation wavelength of $514 \mathrm{~nm}$.

Transmittance spectra of the coatings deposited on the quartz substrates were recorded on a Solid Spec3700 UV-VIS-NIR Shimadzu Spectrophotometer in the wavelength range of $240-900 \mathrm{~nm}$.

The Vickers microhardness was measured on a Vickers M-17 1021 device equipped with optical microscope with a $40 \mathrm{~g}$ load and a loading time of $20 \mathrm{~s}$. Pencil hardness test was also performed for all specimens.

\section{Results and discussion}

The characteristic groups of the ENR and photoinitiator chains are clarified by FTIR spectroscopy in Figure 3. The FTIR spectra of the ENR has confirmed the presence of oxirane rings observed at $907 \mathrm{~cm}^{-1}$ [29]. The broad bands corresponding to aromatic double bond $\mathrm{C}=\mathrm{C}$ vibrations in the phenyl group appeared at $1590 \mathrm{~cm}^{-1}$ for ENR. In the $3000-2750 \mathrm{~cm}^{-1}$ range, two intense bands at 2925 and $2855 \mathrm{~cm}^{-1}$ can be observed due to stretching of the $-\mathrm{CH}_{2}$ groups of the aromatic and aliphatic structures in the chain backbone of the photoinitiator and reactive diluent of $\mathrm{C}_{12} / \mathrm{C}_{14}$ glycidylether [8].

While UV-VIS spectra of the ENR and PI were obtained to measure their transparency in UV and VIS

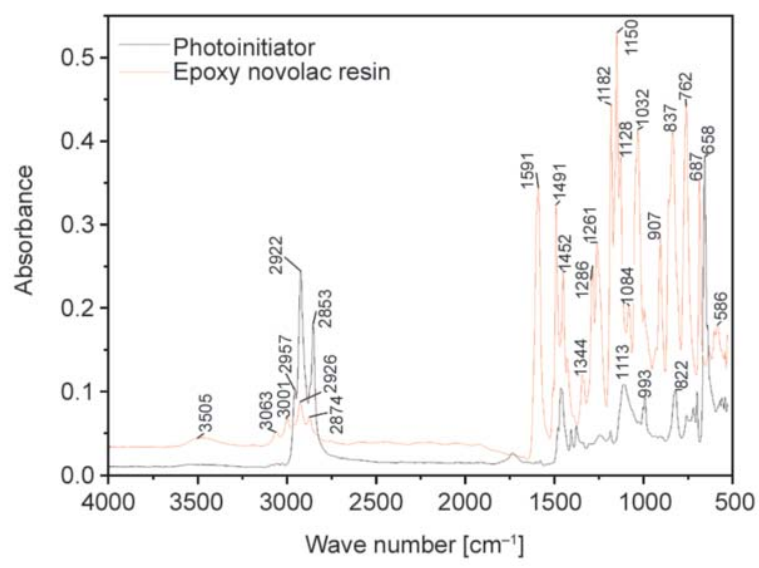

Figure 3. FTIR spectra of photoinitiator and epoxy novolac resin.

light, as shown in Figure 4, the maximum UV absorbance of the $P I$ is in the range 200-225 nm, which suits the Hg lamp emission used, guaranteeing efficient absorption of the UV light by the reactive compound. The ENR absorbs strongly in the wavelength range $250-300 \mathrm{~nm}$.

The possible ENR photopolymerization initiation mechanism is shown in Figure 2. The mechanism of photoactivation for the cationic initiator is described widely in the literature. In the photolysis process, the $P I$ compound produces strong Bronsted acids $\left(\mathrm{H}^{+} \mathrm{X}^{-}\right)$ $[14,35]$ which initiate monomer molecule chain by the oxirane ring opening and development of cationic radicals. The photoinitiation mechanism involves multiple steps. The first step is the generation of an acidic species through UV irradiation of onium salts followed by protonation of first monomer which implies an electrophilic attack of the acidic species on the nucleophilic oxygen of oxirane groups, which in 


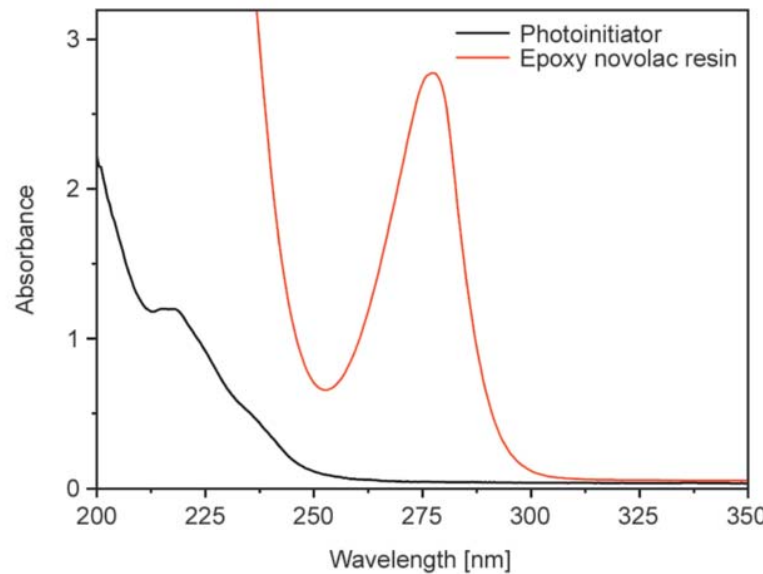

Figure 4. UV spectra of photoinitiator and epoxy novolac resin.

turn results in the formation of secondary onium ion i.e. cationic radicals $[12,13]$. Due to their very high reactivity, radicals have a short life time and, as a result, the curing reaction is very fast. At the next chain propagation by activated chain end (ACE) mechanism and chain growth occurs by living cationic polymerization reactions. Further the reactive diluent of glycidylether inside the reactive mixture also participates in the formation of the crosslinked chain networks. In ACE mechanism, after the formation of secondary onium ion, propagation starts that results in cationic chain growth (Figure 2). It is also considered that the cationic type initiators are not inhibited by oxygen and are superior to those of free radical type [16]. In the termination step different factors play a vital role. Termination can occur with a solvent, monomer or side reaction, where chain transfer reactions through interaction with propagating chains appear between an anion and counterion allowing inactivation of the growing chain and production of inactive species [14]. The use of cationic initiators also benefits from very short curing reaction of only several minutes. When the reaction is complete, a threedimensional network is obtained. In this case a hard material is created due to the short length between linking nodes. Several experimental PI concentrations and UV-irradiation times were used to describe the photopolymerization conditions.

Figure 5 shows top-down optical microscopy (OM) images of the UV-cured ENR coatings on different substrate surfaces. Images in Figure 5a represent the ENR coatings on the glass slides when $1.5 \%$ PI was used with irradiation times from 1 to $50 \mathrm{~min}$. ENR $1.5 \%$ of $P I$ coating on steel irradiated $5 \mathrm{~min}$. is shown in Figure 5b. Figure 5c indicates the optical

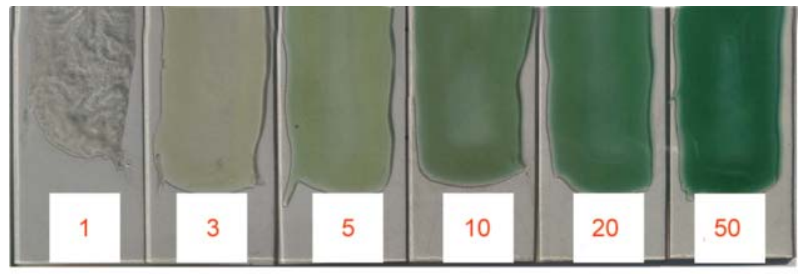

a)

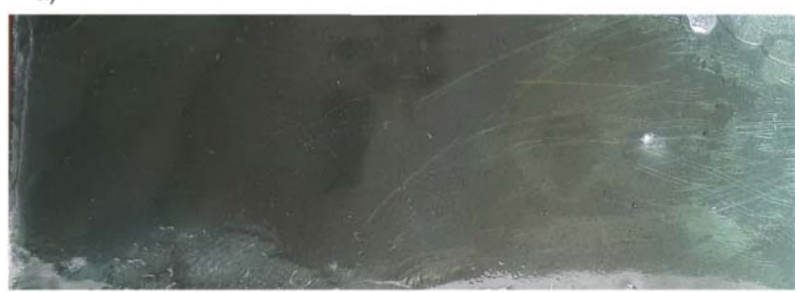

b)

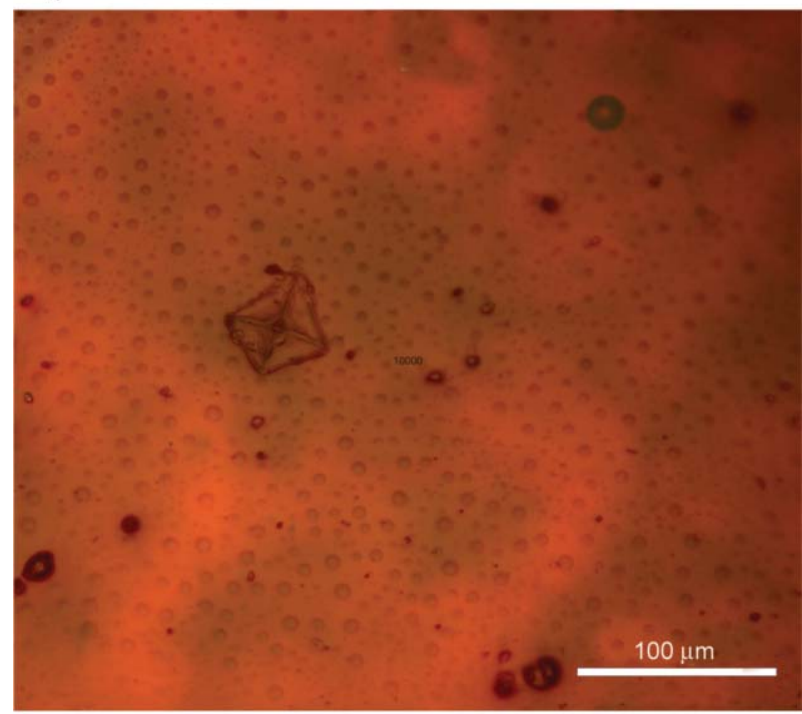

c)

Figure 5. Images of ENR coatings on glass with $1.5 \%$ of $P I$ and irradiation times of $1,3,5,10,20$ and 50 min (a); ENR coating with $1.5 \%$ of $P I$ and irradiation time $5 \mathrm{~min}$ on steel (b); optical microscopy image with hardness indentation for ENR $1.5 \%$ of $P I$ and irradiation time $3 \mathrm{~min}$ (c).

microscopy image at magnification by 10 times with hardness indentation impression for the same sample. As can be seen in the images, the quality of the photo-cured ENR coatings is very good. The coatings have excellent gloss and the surface is without evident defects. Only some defects and voids were generated during coating preparation.

Microhardness measurements and hardness by 'pencil tests' [36] were used as very powerful applied techniques to characterize the outcome of the finished coating photocuring process. As expected, the ENR coating properties are strongly dependent on the photopolymerization cross-linking conditions, as well as on ENR formulation. In the so called 'pencil test', a strip is drawn under a pencil on the sample surface 


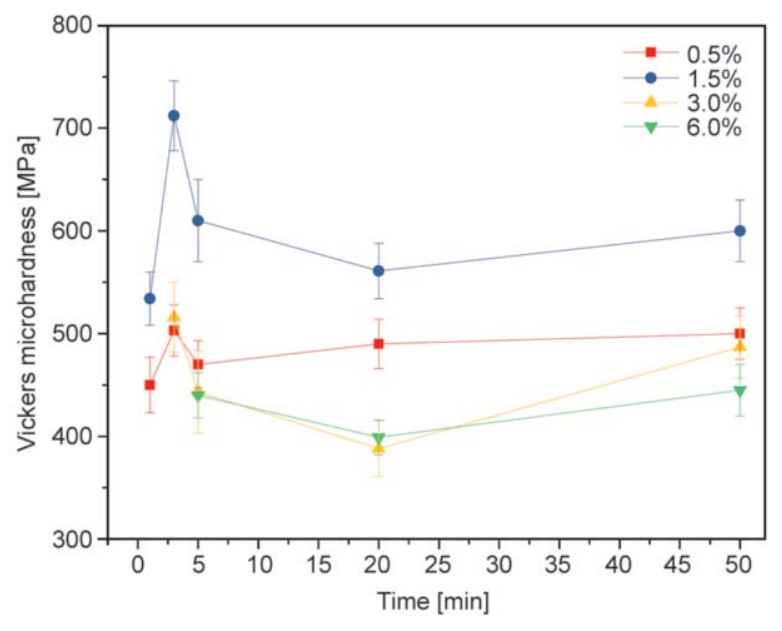

Figure 6. Time dependence of Vickers microhardness of photocured ENR coatings for different PI concentrations.

until a hardness grade is reached which will scratch the surface. The coating is then assigned as graphite hardness HB scale from soft to rigid properties, corresponding to the hardness range from $9 \mathrm{~B}$ to $9 \mathrm{H}$. Application of the 'pencil test' to evaluate the cured epoxy coatings was performed by Bajpai et al. [29] and Aoki and Ichimura [37], who reported very good correlation of 'pencil tests' data with the scratch hardness and cross-linking density measurements. The photo-cured EPR coatings with at least $1.5 \%$ of $P I$ and $3 \mathrm{~min}$. curing time have passed $9 \mathrm{H}$, which passes criteria for protective coating used in maritime and power energy industry. While the experimental results of the Vickers microhardness of the photo-cured coatings showed that $P I$ content and irradiation time strongly influence its absolute values. Figure 6 summarizes the obtained Vickers hardness characteristics of these ENR coatings. It was found that the highest hardness value equal to $712 \mathrm{MPa}$ of coating was received with $1.5 \%$ of $P I$ and 3 min of UV-irradiation

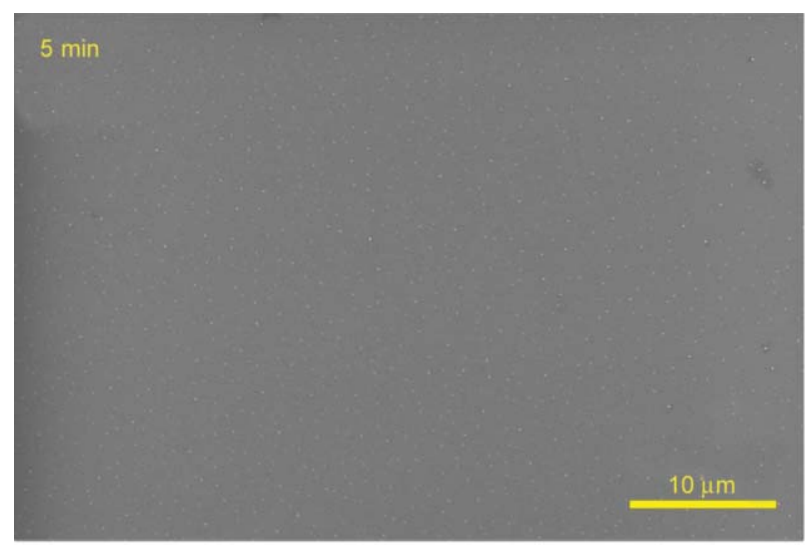

a) due to thee very dense cross-linking network structure developed in the polymer. The obtained microhardness value is higher than the microhardness of the thermally cured two component ENR formulation reference that was almost $700 \mathrm{MPa}$. The optimal irradiation times seem to be almost 3-5 minutes. The surface of irradiated sample is homogeneous, as shown by SEM in Figure 7a. The addition of 0.5, 3.0 or $6.0 \%$ of $P I$ gave lower microhardness values. For example, sample ENR with PI $0.5 \%$ and irradiation time $3 \mathrm{~min}$. showed microhardness of about $503 \mathrm{MPa}$. When the photocuring of the ENR coatings took more than $5 \mathrm{~min}$, the microhardness value decreased, which can be attributed to the polymer photodegradation. The evidence of this suggestion is the appearance of micropores on the surface after irradiation of $50 \mathrm{~min}$, as shown in Figure 7b. The atmospheric oxygen and intense UV-light cause evident voids of $1-2 \mu \mathrm{m}$ on the coating surface of the coating due to degradation of the polymer network and possible vaporization of the low molecular weight compounds [38].

In general, hardness implies resistance to surface deformation against indentation [39]. Thereto, Vickers microindentation hardness of the polymer is related to the macroscopic mechanical properties such as the strength $\sigma$ and the elastic modulus $E$. Hardness $(H)$ is relative to the material strength according to the Tabor relation $H \sim 3 \sigma$ [40]; then, the empirical relation $H \sim E / 10$ is obtained for polymer materials [41]. For the cross-linked epoxy solid state polymers, the relationship is proposed to be modified $E \sim 35.3 f H$ [42], where $f$ is the relative fluctuation free volume $(f=0.11)$, which is proposed to be the quantitative characteristic of chain network disorder degree as calculated from hole and the free volume quantity theory of the Simha-Boyer [43]. Thereto, the elastic

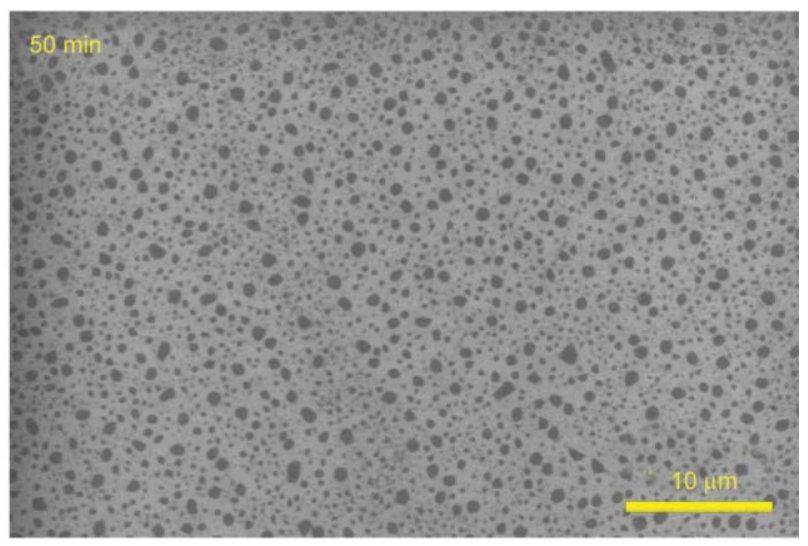

b)

Figure 7. FE-SEM images of photocured ENR coatings with $P I=1.5 \%$ at irradiation times of 5 (a) and 50 min (b). 
modulus obtained from the above relations can be used to calculate the cross-linking density based on the Flory-Rehner theory of rubber elasticity [44] using the elementary Gaussian statistics conditions of the polymer chain [45], which corresponds to the empirical approach for any rigid chain network structure of the unswollen solid state polymers by the equation given in the form $G=A \rho R T / M_{\mathrm{c}}$ [46], where $\rho$ is the polymer density $[\mathrm{g} / \mathrm{cc}], G$ is the bulk modulus $[\mathrm{MPa}], R$ is the universal gas constant $(8.314 \mathrm{~J} / \mathrm{mol} / \mathrm{K}), M_{\mathrm{c}}$ is the molecular weight between cross-links [g/mol], $T$ is the absolute temperature $(298 \mathrm{~K})$ and $A$ is the coefficient determined by the trifunctional branching units of the polymer network nodes. $A$ is proposed as a characteristic value of multifunctional nodes according to the molecular theory of elasticity for the chain networks with the junctions described by Flory $[47,48]$. In a unit of volume of the polymer, the cross-link density $N[\mathrm{~mol} / \mathrm{cc}]$ is connected to the molecular weight between cross-links by the relation $N=\rho A_{0} / 2 M_{\mathrm{c}}$ [42], where $A_{0}$ is Avogadro's number $\left(6.022 \cdot 10^{23} 1 / \mathrm{mol}\right)$. The received network density values corresponds well to the general cross-linking polymerization theory [42], which predicts that the highest rigidity of the thermoset polymer is obtained for the polymer chain network with large cross-linking densities and close distance between network nodes [49]. For example, composition ENR with $P I=1.5 \%$ after 3 min irradiation is characterized by the crosslinking density characteristics $M_{\mathrm{c}}=322.6 \mathrm{~g} / \mathrm{mol}$ and $N=1.82 \cdot 10^{3} \mathrm{~mol} / \mathrm{cc}$. While epoxy resin stoichiometrically cured with metaphenylene diamine showed $M_{\mathrm{c}}=\mathrm{g} / \mathrm{mol}$ [50]. Also, it also conforms to the theoretical calculations [42] and the molecular dynamic modeling [51] of

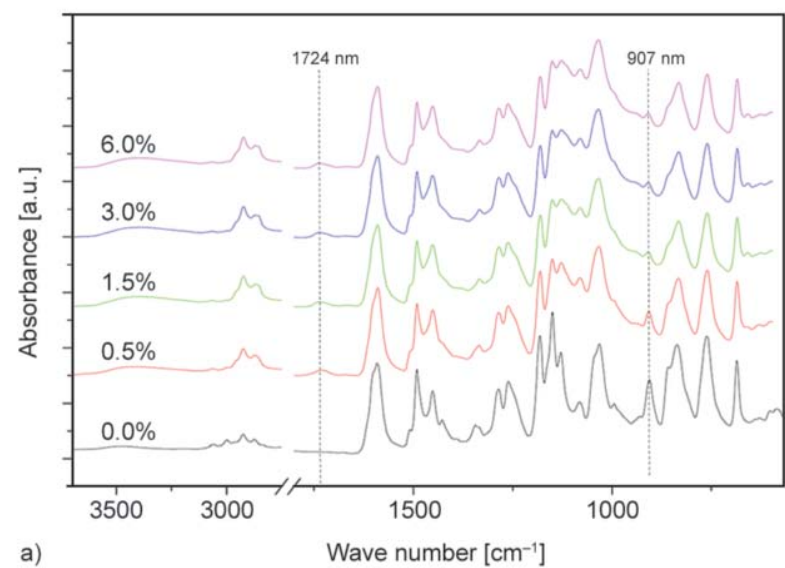

cross-linked epoxy by resins Liu and Naumann [50]. It is sure that the epoxy/curing agent stoichiometric ratio and cationic initiator content will guide the final cross-linking density of the epoxide polymer. The values of cross-linking densities $N$ are 1.82, 2.58, and $1.87 \cdot 10^{3} \mathrm{~mol} / \mathrm{cc}$ for ENR with PI $0.5,1.5$, and $3 \%$ correspondingly. Thereto, the optimal PI concentration is equal to $1.5 \%$. It is obvious that generation of the active and stable radicals by photoinitiator decomposition during UV-irradiation can further propagate the polymer chain network growth, while the crosslinking density is always a function of the initiator content [52]. The lower content, besides the optimal concentration of initiator, develops fewer chain crosslinks [17].

The irradiation time also strongly influences the ENR coating properties. The experimental results (see Figure 6) show that 3 min of UV-irradiation gives the highest microhardness values for the ENR. Further increases in irradiation time can only decrease the microhardness properties of the ENR coating, because photodegradation of the polymer generally occurs at high irradiation times [38]. The UV-irradiation process of the ENR was studied by FTIR, UV-VIS and RAMAN spectroscopies, which data can complement each other. Decker et al. [53] has recommended using changes in spectra to study both processes of the photopolymerization and photodegradation for the highly cross-linked epoxy polymers.

FTIR spectral data for photopolymerized ENR coatings are shown in Figure 8. The influence of $P I \%$ content and irradiation time on the linkages can be evaluated. ENR contains phenyl, ketone linkage and epoxy group. The band of phenyl $\mathrm{C}-\mathrm{H}$ stretch vibrations appears at around $3000-2900 \mathrm{~cm}^{-1}$. The band

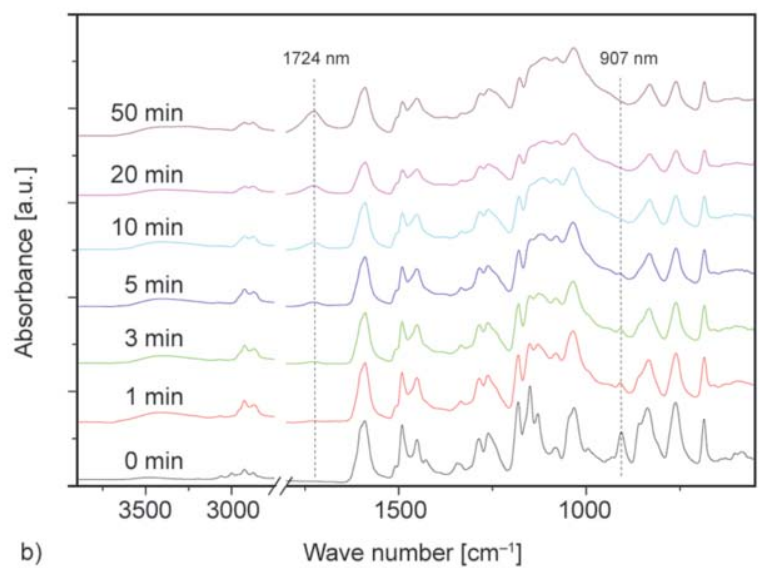

Figure 8. FTIR absorption spectra of ENR for different $P I$ concentrations and an irradiation time of 5 min (a); time evolution of FTIR absorption spectra of ENR with $P I=1.5 \%$ (b). 
at $1503 \mathrm{~cm}^{-1}$ and the doublet around $1450 \mathrm{~cm}^{-1}$ are due to $\mathrm{C}=\mathrm{C}$ stretch vibrations of the aromatic ring [54]. Photocured ENR exhibit bands in the region of $1724 \mathrm{~cm}^{-1}$, which confirms the presence of carbonyl group $\mathrm{CO}$ acyclic stretch in the ketone linkage developed during photopolymerization. The asymmetrical ether $\mathrm{C}-\mathrm{O}$ stretching vibration at $1260 \mathrm{~cm}^{-1}$ and the symmetrical ether $\mathrm{C}-\mathrm{O}$ stretching vibration at $1014 \mathrm{~cm}^{-1}$ remained essentially constant after long UV irradiation. The absorption at $907 \mathrm{~cm}^{-1}$ peak is attributed to epoxy ring $\mathrm{C}-\mathrm{O}-\mathrm{C}$ vibrations [55]. As can be seen, the epoxy band disappeared completely for PI $1.5 \%$ and a UV irradiation time of $1 \mathrm{~min}$. due to the opening of oxirane rings during the photocuring process. The $\mathrm{C}-\mathrm{O}$ linkage band absorption increase appears for all $P I$ compositions and at all irradiation times directly after $1 \mathrm{~min}$. of the photopolymerization in the region of $1724 \mathrm{~cm}^{-1}$. Somewhat the carbonyl groups can develop as polymer end groups in the photolysis process for novolac epoxy resins as it was reported in the literature $[52,55]$. The ratio $I_{1724 \mathrm{~cm}-1} /$ $I_{907 \mathrm{~cm}-1}$, corresponding to the absorption bands of $\mathrm{CO}$ and $\mathrm{C}-\mathrm{O}-\mathrm{C}$, are calculated to evaluate the process

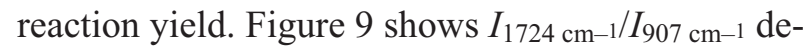
pendences from the photoinitiator content and irradiation time. This demonstrates that the epoxy groups decompose, and carbonyl linkages develop in the photocuring process. Increased initiator content gives a higher yield for the $I_{1724 \mathrm{~cm}_{-1} 1} / I_{907 \mathrm{~cm}-1}$ ratio. At small irradiation times, the polymer chain cross-linking reactions dominate, which gives an almost linear de-

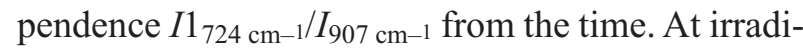
ation times longer than $5 \mathrm{~min}$, the slope of the curve decreases, which means that there are two different rates that show the change from the photocuring

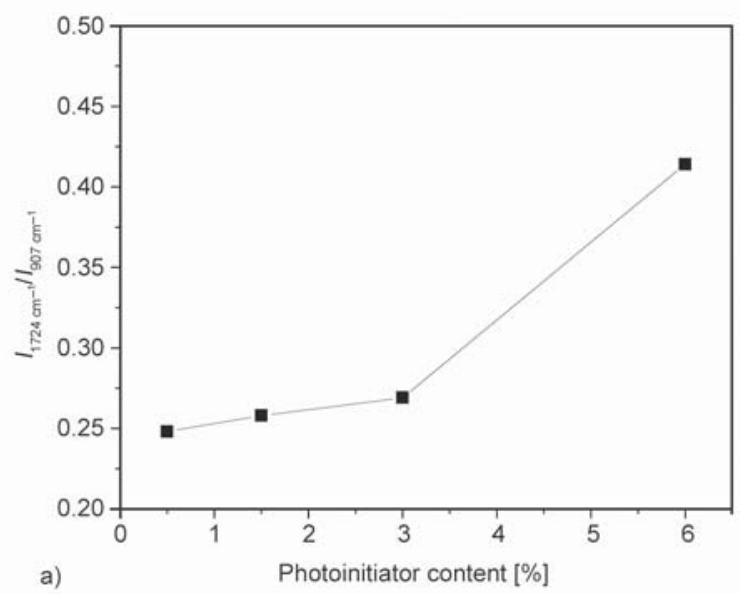

reaction mechanism to the side photochemical reactions of the polymer chains identified as sequential increase of the carbonyl groups which can correspond as polymer chain end groups [52]. The change in slope could be also due to the fact that as the crosslinking reaction proceeds the epoxy groups are less accessible to the attack of monomer or growing oxonium chains, and this results in the decrease of photopolymerization rate and conversion [56].

We have supposed that ENR photopolymerization was completed at an irradiation time of at least $6 \mathrm{~min}$ according to Figure 9. It is also clear that irradiation times longer than 6 min can additionally induce the photodegradation of polymer networks. It is indicated the cross-linked network of the epoxy novolac resin shows characteristic Raman spectra peaks at 1242 , and $1084 \mathrm{~cm}^{-1}$ attributed to $-\mathrm{C}-\mathrm{O}$, and $-\mathrm{C}-\mathrm{O}-\mathrm{C}$ groups, respectively; while the peaks at 915 and $828 \mathrm{~cm}^{-1}$ are directly related to the stretching $\mathrm{C}-\mathrm{O}-\mathrm{C}$ and $\mathrm{C}-\mathrm{O}$ of oxirane groups [57]. The process of the epoxy conversion was complementary monitored by changes in the band corresponding to the oxirane group vibrations at $1086 \mathrm{~cm}^{-1}$ shown in the experimental Raman spectra (Figure 10). Its peak intensity has been shown to strongly decrease increasing the irradiation times; as well as Kim and Kim [58] has reported that the number of epoxy groups decreased with two component epoxy mixing time as represented in Raman spectra. However, some oxirane traces remained even at irradiation times of 20 and $50 \mathrm{~min}$. At low irradiation times, very weak alkyl $\mathrm{CH}_{3}$ stretch vibration is revealed at $250 \mathrm{~cm}^{-1}$.

The ENR coatings photo-curing were also monitored by changes in the UV spectra shown in Figure 11. UV spectra have been found to be more sensitive to

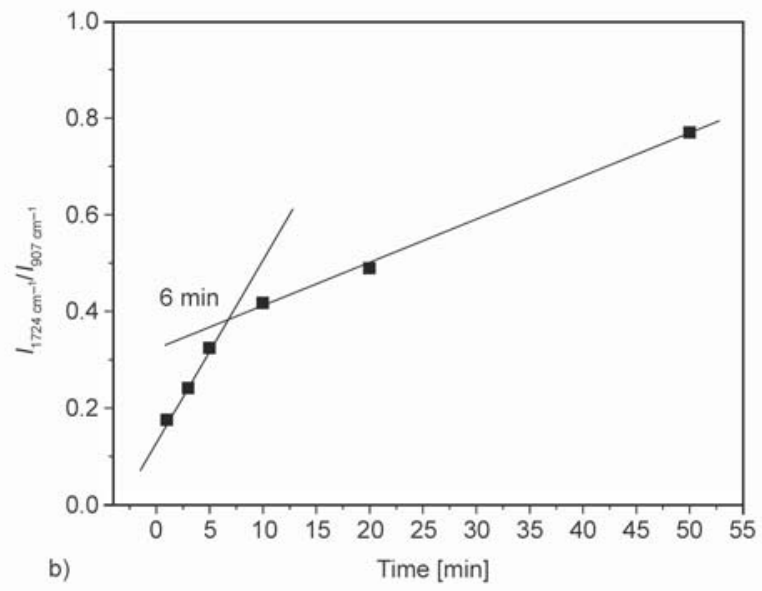

Figure 9. PI concentration (a) and irradiation time (b) dependences of $I_{1724 \mathrm{~cm}-1} / I_{907 \mathrm{~cm}-1}$ ratio obtained from FTIR absorption spectra. 


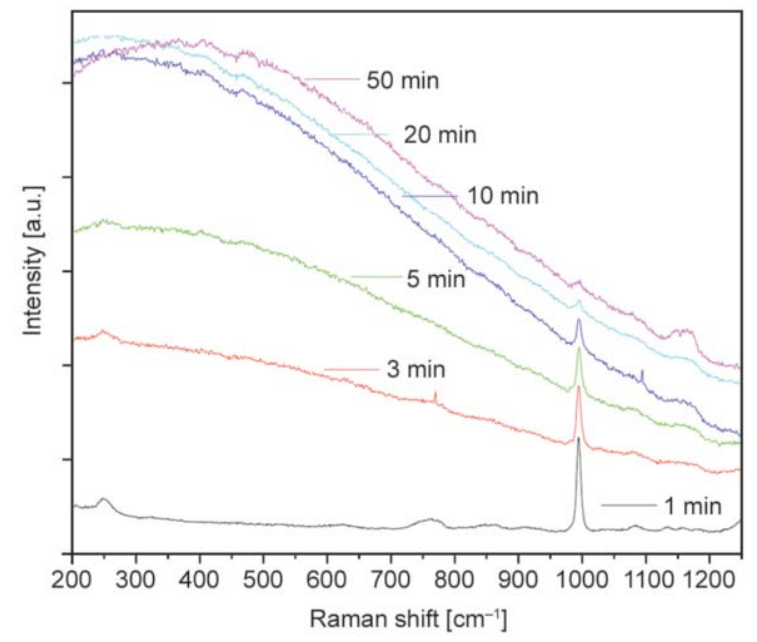

Figure 10. Time evolution of Raman spectra of ENR with $P I=1.5 \%$.

evaluate the possible crosslinking and photodegradation of the ENR polymer chains. The UV-irradiation of the ENR revealed a significant increase in the absorbance i.e. decreases of the transmittance in the 300-700 $\mathrm{nm}$ region. The saturated carbonyls absorb between 280 and $300 \mathrm{~nm}$, alpha-beta unsaturated carbonyls around $320 \mathrm{~nm}$ [54]. Possible degradation of ENR polymer might have been anticipated on the grounds that the cured coatings would contain photoactive materials, e.g., unreacted initiators, initiator fragments and carbonyl groups present as polymer end groups [52]. UV irradiation caused a decrease of the transmittance till the minimum of $20 \%$ at wavelength of $607 \mathrm{~nm}$ of aromatic chromophores. The 10-50 min. UV-irradiation provokes the photochemical reactions of the polymer chains that was experimentally testified as decrease of the hardness of the polymer coatings due to the observed increase of the surface porosity. However, it is depends strongly

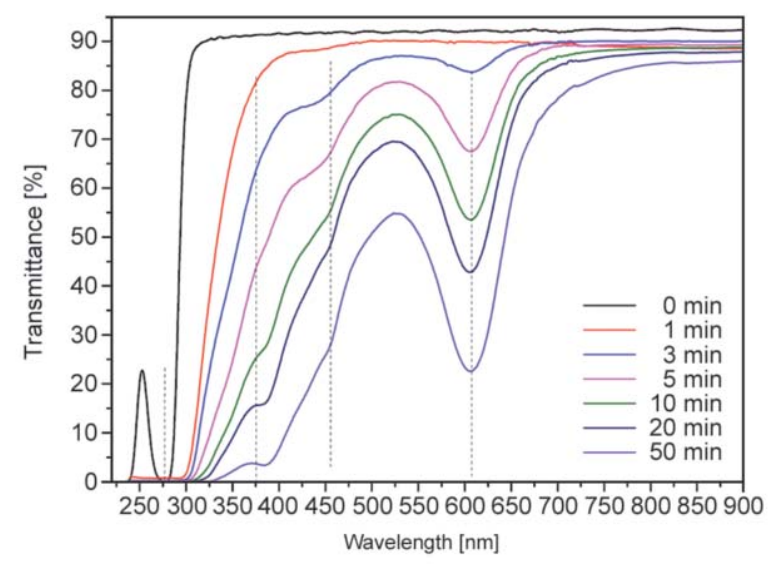

Figure 11. Time evolution of UV-VIS transmittance spectra of ENR with $P I=1.5 \%$. photoinitator chemistry and content [59]. Generally, coating systems containing iodonium $\mathrm{SbF}_{6}$ type salts exhibited higher yellowness and lower hardness in long-term than based polymers based on sulfonium hexafluorophosphates salts [60].

Perhaps somewhat surprisingly it turned out that the pure epoxy novolac resin (derived from formulations not containing a photoinitiator) and photoinitiator itself did not display any change in the color of the substance during the irradiation model experiments. While the main source of instability is the photoinitiator residues, with those resins containing polyether and aromatic groups being the worst performers [17]. The developed system of conjugated $\pi$ bonds during the photolysis of branched aromatic chains networks causes the molecule to absorb light in the visible range [61].

Thereto, the new absorbance maximum was realized at 375 and $607 \mathrm{~nm}$, which characterizes the photolysis and rearrangements of the aromatic structure and formation of chromophore moieties [32]. Figure 12 shows the time-dependent absorption of bands 375 and $607 \mathrm{~nm}$ of ENR with $P I=1.5 \%$, which were calculated by the deconvolution of the transmittance spectral data. It reveals that the polymer side reactions begin after almost 6 min irradiation. It corresponds well to the photodegradation of the polymer chains revealed previously using FTIR analysis. As well as other authors report that FTIR spectroscopy performed on the surface of specimens indicated that UV exposure in the presence of water condensation resulted in the photodegradation by formation of hydroxyl groups on the surface, which further promoted cross-linking reactions on the surface resulting in

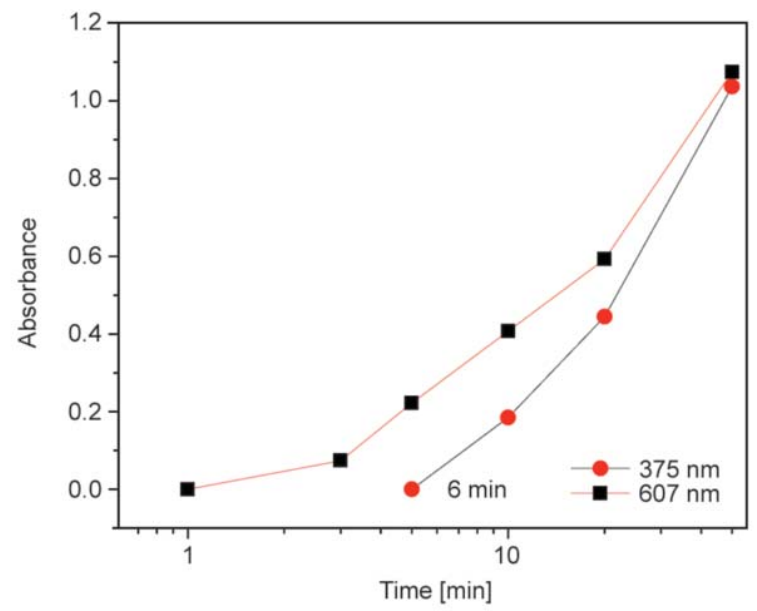

Figure 12. Time-dependent absorption of bands 375 and $607 \mathrm{~nm}$ of ENR with $P I=1.5 \%$. 
degradation [58]. At the same time, spectra recorded by FTIR spectroscopy detected chain scission had a greater contribution to epoxy degradation [62].

According to the literature there exist two types of products which the phenoxy radical may generate during the photodegradation process through the photo-Fries rearrangements [63]. In a first instance there is the possibility of the phenoxy radical to generate phenol via extraction of a hydrogen atom from vicinal entities. In a second instance the phenoxy radical may lead to the formation of an acyl phenol through recombination with an acyl radical and hydrogen extraction, after previously passing in the form of one of the two cyclohexadienonic intermediates [64]. Phenoxy resins are attributed to the high oxidizability of methylene groups in $\alpha$-position to the oxygen atom of the ether groups [65]. For instance, Chae et al. [61] report irradiation of the aromatic polymers that led to its color change produced in the irradiated treated area of the polymer film containing phenolic or aromatic amino species due to the chain photo cross-linking and rearrangement through the photo-Fries type. While a subsequent UV light illumination also induces the structural changes in the chemical composition by photo-Fries rearrangement of the polymer phenyl ester groups that lead to significant changes in the refractive index of the polymeric materials [66].

\section{Conclusions}

For the first time, the UV-light-induced curing of branched epoxy novolac resin was reported. The cationic photopolymerization of the epoxy novolac resin coatings was initiated by the photodecomposition of bis(4-dodecylphenyl) iodonium hexaflurorantimonate. Photoinitiator content and irradiation time are the main characteristics affecting the exploitation properties of the epoxy novolac resin coatings. The prepared coatings have passed the 'pencil test' of 9H; while, the Vickers hardness have been equal to $712 \mathrm{MPa}$. The obtained hardness of the photocured coatings is equal to the thermally cured two component epoxy novolac resin formulation. The optimal photoinitiator content and the irradiation times were found to be $1.5 \%$ and 3 minutes, respectively, due to the dense cross-linking polymer network structure which was developed. UV irradiation times longer than $6 \mathrm{~min}$. resulted in the photodegradation of the epoxy novolac resin polymer. This process was revealed by FTIR, UV-VIS and Raman spectroscopy methods. It also resulted in the in hardness characteristics due to the voids and defects which developed on the coating surface, as clearly shown by SEM. Finally, the developed branched epoxy novolac resin photopolymerization technology can be applied to receive protective coatings for diverse applications in power generation and maritime industries, where the thermal curing process of two-component resins are completely unacceptable.

\section{Acknowledgements}

The financial support of the RTU Scientific Platform for Science and Innovation Project ND:YAG laser induced photopolymerization of Novolac polymers is gratefully acknowledged.

\section{References}

[1] Ellis B.: Chemistry and technology of epoxy resins. Springer, Berlin (1993).

[2] Ratna D.: Handbook of thermoset resins. Rapra, Telford (2009).

[3] Burton B. L.: Amine curing of epoxy resins: Options and key formulation considerations. Paint and Coatings Industry, 22, 68-77 (2006).

[4] Ren S-P., Lan Y-X., Zhen Y-Q., Ling Y-D., Lu M-G.: Curing reaction characteristics and phase behaviors of biphenol type epoxy resins with phenol Novolac resins. Thermochimica Acta, 440, 60-67 (2006). https://doi.org/10.1016/j.tca.2005.10.009

[5] Dodiuk H., Goodman S.: Handbook of thermoset plastics. William Andrew, Boston (2014).

[6] McFedries R.: The issue of coatings. Maritime by Holland, 61, 58-61 (2012).

[7] Cohen G.: UV/EB market trends. RadTech Report, 2012, 44-48 (2012).

[8] Wood L.: Radiation cured products market - global industry analysis, size, share, growth, trends and forecast 2013-2019. Transparency Market Research Reports (2014).

[9] Mark H. F.: Encyclopedia of polymer science and technology. Wiley, London (2003).

[10] Boey F., Rath S. K., Ng A. K., Abadie M. J. M.: Cationic UV cure kinetics for multifunctional epoxies. Journal of Applied Polymer Science, 86, 518-525 (2002). https://doi.org/10.1002/app.11041

[11] Davidson R. S., Holman R. J.: Developments and trends in radiation curing. Review of Progress in Coloration and Related Topics, 33, 46-58 (2003). https://doi.org/10.1111/j.1478-4408.2003.tb00143.x

[12] Decker C.: Photoinitiated crosslinking polymerisation. Progress in Polymer Science, 21, 593-650 (1996). https://doi.org/10.1016/0079-6700(95)00027-5 
[13] Atif M., Bongiovanni R., Yang J.: Cationically UV-cured epoxy composites. Polymer Reviews, 55, 90-106 (2015).

https://doi.org/10.1080/15583724.2014.963236

[14] Decker C., Viet T. N. T., Thi H. T.: Photoinitiated cationic polymerization of epoxides. Polymer International, 50, 986-997 (2001).

https://doi.org/10.1002/pi.730

[15] Crivello J. V.: The discovery and development of onium salt cationic photoinitiators. Journal of Polymer Science, Part A: Polymer Chemistry, 37, 4241-4254 (1999). https://doi.org/10.1002/(SICI)10990518(19991201)37:23<4241::AID-POLA1>3.0.CO;2-R

[16] Sangermano M., Razza N., Crivello J. V.: Cationic UVcuring: Technology and applications. Macromolecular Materials and Engineering, 299, 775-793 (2014). https://doi.org/10.1002/mame.201300349

[17] Decker C.: UV radiation curing chemistry. Pigment and Resin Technology, 30, 278-286 (2001). https://doi.org/10.1108/03699420110404593

[18] Crivello J. V.: UV and electron beam-induced cationic polymerization. Nuclear Instruments and Methods in Physics Research Section B: Beam Interactions with Materials and Atoms, 151, 8-21 (1999). https://doi.org/10.1016/S0168-583X(99)00109-3

[19] Li F., Bao J., Chen X., Bao H., Wang H.: Factors influencing EB curing of epoxy matrix. Radiation Physics and Chemistry, 63, 557-561 (2002).

https://doi.org/10.1016/S0969-806X(01)00620-X

[20] Shi S., Croutxé-Barghorn C., Allonas X.: Photoinitiating systems for cationic photopolymerization: ongoing push toward long wavelengths and low light intensities. Progress in Polymer Science, 65, 1-41 (2017). https://doi.org/10.1016/j.progpolymsci.2016.09.007

[21] Jiang T., Koch J., Unger C., Fadeeva E., Koroleva A., Zhao Q., Chichkov B. N.: Ultrashort picosecond laser processing of micro-molds for fabricating plastic parts with superhydrophobic surfaces. Applied Physics A, 108, 863-869 (2012).

https://doi.org/10.1007/s00339-012-6985-4

[22] Paul G. L., Klick D. I., Akerman M. A., Supurovic D., Tsuda H., Wilson G. J., O’Neill, J. A.: Excimer laser polymerisation for industry. Proceedings of the ACS Division of Polymeric Materials Science and Engineering, 60, 537-541 (1989).

[23] Endruweit A., Johnson M. S., Long A. C.: Curing of composite components by ultraviolet radiation: A review. Polymer Composites, 27, 119-128 (2006). https://doi.org/10.1002/pc.20166

[24] ISO: 21348 Definitions of solar irradiance spectral categories (2007).

[25] Liaw I. I., Boyd I. W.: The development and application of UV excimer lamps in nanofabrication. in 'NATO Science for Peace and Security Series B: Physics and Biophysics' Springer, Dordrecht, 61-76 (2008). https://doi.org/10.1007/978-1-4020-8903-9 4
[26] Nair C. P. R.: Advances in addition-cure phenolic resins. Progress in Polymer Science, 29, 401-498 (2004). https://doi.org/10.1016/j.progpolymsci.2004.01.004

[27] Knop A., Pilato L. A.: Phenolic resins chemistry, Applications and performance. Springer, Berlin (1985).

[28] Gardziella A., Pilato L. A., Knop A.: Phenolic resins: Chemistry, applications, standardization, safety and ecology. Springer, New York (2000).

[29] Bajpai M., Shukla V., Habib F.: Development of a heat resistant UV-curable epoxy coating. Progress in Organic Coatings, 53, 239-245 (2005). https://doi.org/10.1016/j.porgcoat.2004.12.010

[30] Vanaja A., Rao R. M. V. G. K.: Synthesis and characterisation of epoxy-novolac/bismaleimide networks. European Polymer Journal, 38, 187-193 (2002). https://doi.org/10.1016/S0014-3057(01)00094-5

[31] He H., Li K., Wang J., Wang J., Gu J., Li R.: Effects of novolac resin modification on mechanical properties of carbon fiber/epoxy composites. Polymer Composites, 32, 227-235 (2011). https://doi.org/10.1002/pc.21037

[32] Wang M., Xu X., Ji J., Yang Y., Shen J., Ye M.: The hygrothermal aging process and mechanism of the Novolac epoxy resin. Composites Part B: Engineering, 107, 1-8 (2016).

https://doi.org/10.1016/j.compositesb.2016.09.067

[33] Keehan D.: Higher cross-link density coatings keep chemical cargoes purer. Tanker Operator, 2016(5), 53 (2016).

[34] Hsieh T. H., Wang T. L., Ho K. S., Wang Y. Z.: Chemorheological analysis of an epoxy-novolac molding compound. Polymer Engineering and Science, 40, 418-429 (2000). https://doi.org/10.1002/pen.11175

[35] Crivello J. V., Lam J. H. W.: Diaryliodonium salts. A new class of photoinitiators for cationic polymerization. Macromolecules, 10, 1307-1315 (1977). https://doi.org/10.1021/ma60060a028

[36] ASTM D3363: Standard test method for film hardness by pencil test (2011).

[37] Aoki K. i., Ichimura K.: Branched base-amplifying oligomers enhancing UV-curing of epoxy resins. Macromolecular Chemistry and Physics, 210, 1303-1309 (2009). https://doi.org/10.1002/macp.200900178

[38] Rosu D., Visakh P.: Photochemical behavior of multicomponent polymeric-based materials. Springer, Cham (2016).

[39] Calleja F. J. B., Fakirov S.: Microhardness of polymers. Cambridge University Press, Cambridge (2007).

[40] Tabor D.: The hardness and strength of metals. Journal of the Institute of Metals, 79, 1-18 (1951).

[41] Michler G. H., Balta-Calleja F. J.: Mechanical properties of polymers based on nanostructure and morphology. CRC Press, London (2016).

[42] Magomedov G. M.: Structure and properties of crosslinked polymers. Smithers Rapra, Shropshire (2011). 
[43] Boyer R. F.: $\Omega C_{\mathrm{p}} T_{\mathrm{g}}$ and related quantities for high polymers. Journal of Macromolecular Science Part B: Physic, 7, 487-501 (1973).

https://doi.org/10.1080/00222347308207880

[44] Flory P. J., Rehner J.: Statistical mechanics of crosslinked polymer networks I. Rubberlike elasticity. The Journal of Chemical Physics, 11, 512-520 (1943). https://doi.org/10.1063/1.1723791

[45] Tatara Y.: Statistical derivation of similar form to the Mooney-Rivlin expression for unswollen elastomers. The Journal of Chemical Physics, 61, 1147-1150 (1974). https://doi.org/10.1063/1.1681988

[46] Treloar L. R. G.: The physics of rubber elasticity. Oxford University Press, Oxford (1975).

[47] Flory P. J.: Molecular theory of rubber elasticity. Polymer Journal, 17, 1-12 (1985).

https://doi.org/10.1295/polymj.17.1

[48] Flory P. J.: Molecular size distribution in three dimensional polymers. II. Trifunctional branching units. Journal of the American Chemical Society, 63, 3091-3096 (1941). https://doi.org/10.1021/ja01856a062

[49] Sperling L. H.: Introduction to physical polymer science. Wiley, New York (2005).

[50] Liu S. H., Nauman E. B.: Effect of cross-linking density on the toughening mechanisms of rubber-modified thermosets. Journal of Materials Science, 26, 6581-6590 (1991). https://doi.org/10.1007/BF00553681

[51] Bandyopadhyay A., Valavala P. K., Clancy T. C., Wise K. E., Odegard G. M.: Molecular modeling of crosslinked epoxy polymers: The effect of crosslink density on thermomechanical properties. Polymer, 52, 24452452 (2011).

https://doi.org/10.1016/j.polymer.2011.03.052

[52] Davidson R. S.: Radiation curing. Rapra, Shropshire (2001).

[53] Decker C., Viet N. T., Decker D., Weber-Koehl E.: UVradiation curing of acrylate/epoxide systems. Polymer, 42, 5531-5541 (2001). https://doi.org/10.1016/S0032-3861(01)00065-9

[54] Simbürger H., Kern W., Hummel K., Hagg C.: Photoreactions in polymers containing benzil units: A comparative study under excimer laser and Hg-lamp irradiation. Polymer, 41, 7883-7897 (2000). https://doi.org/10.1016/S0032-3861(00)00172-5

[55] Li Y., Zhang Z.: Curing of epoxy resin induced by femtosecond laser pulse. Journal of Wuhan University of Technology-Materials Science Edition, 20, 65-68 (2005). https://doi.org/10.1007/BF02841285

[56] Crivello J. V., Lam J. H. W.: Photoinitiated cationic polymerization of epoxy resins. in 'Epoxy resin chemistry' (ed.: Bauer R. S.) American Chemical Society New York, 39, 31-35 (1978).

https://doi.org/10.1021/bk-1979-0114.ch001
[57] Szeluga U., Pusz S., Kumanek B., Myalski J., Hekner B., Tsyntsarski B., Oliwa R., Trzebicka B.: Carbon foam based on epoxy/Novolac precursor as porous microfiller of epoxy composites. Composites Part A: Applied Science and Manufacturing, 105, 28-39 (2018).

https://doi.org/10.1016/j.compositesa.2017.11.004

[58] Kim W. G., Kim H. S.: B-stage characterization of $o$ cresol Novolac epoxy resin system using raman spectroscopy and matrix-assisted laser desorption/ionization mass spectrometry. Journal of Applied Polymer Science, 76, 1940-1946 (2000).

https://doi.org/10.1002/(SICI)10974628(20000624)76:13<1940::AID-APP11>3.0.CO;2-H

[59] Kowandy C., Ranoux G., Walo M., Vissouvanadin B., Teyssedre G., Laurent C., Berquand A., Molinari M., Coqueret X.: Microstructure aspects of radiation-cured networks: Cationically polymerized aromatic epoxy resins. Radiation Physics and Chemistry, 143, 20-26 (2018).

https://doi.org/10.1016/j.radphyschem.2017.09.006

[60] Kowalczyk K., Kowalczyk A.: Influence of cationic photoinitiator type on properties of coating materials based on cycloaliphatic and glycidyl epoxy resins. Progress in Organic Coatings, 112, 1-8 (2017).

https://doi.org/10.1016/j.porgcoat.2017.06.024

[61] Chae K. H., Yang U. C., Lee M. K.: Photo-induced aminobenzoate group formation on a polymeric photobase generator bearing $N$-phenylcarbamate groups and its application to color imaging material. Polymer, 55, 2362-2368 (2014).

https://doi.org/10.1016/j.polymer.2014.03.037

[62] Kim H., Urban M. W.: Molecular level chain scission mechanisms of epoxy and urethane polymeric films exposed to $\mathrm{UV} / \mathrm{H}_{2} \mathrm{O}$. Multidimensional spectroscopic studies. Langmuir, 16, 5382-5390 (2000).

https://doi.org/10.1021/la990619i

[63] Kyrychenko V., Smolyakov G., Zagniy V., Vretik L., Paskal L., Syromyatnikov V., Yaroshchuk O.: Photochemistry of bis-methacrylic polymers and alignment of liquid crystals. Molecular Crystals and Liquid Crystals, 496, 278-292 (2008).

https://doi.org/10.1080/15421400802451873

[64] Rivaton A., Gardette J. L.: Photo-oxidation of aromatic polymers. Angewandte Makromolekulare Chemie, 261-262, 173-188 (1998).

[65] Rivaton A.: Recent advances in bisphenol-A polycarbonate photodegradation. Polymer Degradation and Stability, 49, 163-179 (1995). https://doi.org/10.1016/0141-3910(95)00069-x

[66] Edler M., Mayrbrugger S., Fian A., Trimmel G., Radl S., Kern W., Griesser T.: Wavelength selective refractive index modulation in a ROMP derived polymer bearing phenyl- and ortho-nitrobenzyl ester groups. Journal of Materials Chemistry C, 1, 3931-3938 (2013). https://doi.org/10.1039/c3tc00006k 